\title{
Feasibility Study of Sustainable Energy Sources in A Fossil Fuel Rich Country
}

\author{
Abdullah A. Almehizia, Student Member, IEEE, Hussein M. K. Al-Masri, Member, IEEE, \\ and Mark Ehsani, Life Fellow, IEEE
}

\begin{abstract}
This paper represents an approach for renewable energy sources integration with the existing grid. Unique types of loads can be exploited to allow for a sustainable solution to energy integration. A case study of Saudi Arabia is investigated where desalination plants coupled with a water storage tank is utilized to mitigate the variability of renewable sources. A hybrid photovoltaic-wind turbine generator system (PV-WTG) is proposed. The results indicate two critical points. First, even in a fossil fuel-rich country, sustainable renewable sources are economically feasible. The second point is that the typical storage element (i.e., batteries), is not always the best candidate for energy storage as in the case of desalination plants. Instead, storing the excess energy as water in a storage tank is economical and less prone to failures as compared to large-scale batteries. The problem is formulated as an optimization problem and solved using heuristic techniques.
\end{abstract}

Index Terms-Renewable energy sources, energy storage, load models, meta-heuristic, cost savings

\section{NOMENCLATURE}

$G_{T} \quad$ Total solar irradiance on a tilted surface $\left(\mathrm{W} / \mathrm{m}^{2}\right)$.

$T_{C}, T_{A} \quad$ Solar cell and ambient temperatures at the location $\left({ }^{\circ} \mathrm{C}\right)$.

NOCT Nominal operation cell temperature $\left({ }^{\circ} \mathrm{C}\right)$.

$P_{m p p}^{r e f}$ Maximum power output of PV panel at Standard Test Conditions (STC) (W).

$G_{\text {ref }} \quad$ Solar radiation at Standard Test Conditions (STC) $\left(\mathrm{W} / \mathrm{m}^{2}\right)$.

$T_{C}^{r e f} \quad$ Solar cell temperature at Standard Test Conditions (STC) $\left({ }^{\circ} \mathrm{C}\right)$.

$\alpha_{P_{m p p}}, d_{p v}$ PV power temperature coefficient and derating factor $\left(\% /{ }^{\circ} \mathrm{C}, \%\right)$.

$\eta_{\text {conv }}, \alpha \quad$ Efficiency of converter and shear coefficient $(\%)$.

$v_{c i}, v_{c o}, v \quad$ Cut in, cut out and hub height wind speeds $(\mathrm{m} / \mathrm{s})$.

$P_{w t}^{\text {rated }} \quad$ Wind turbine rated power output (MW).

$P_{p v}, P_{w t} \quad$ Photovoltaic and wind turbine power output (MW).

$\varepsilon_{g}, \varepsilon_{v} \quad$ Solar radiation and wind speed forecast error random variables.

$\Xi, \varepsilon \quad$ Output variable from the MCS and and coefficient of variation.

$E(\Xi) \quad$ Expected value of $\Xi$.

$\sigma(E(\Xi)) \quad$ Standard deviation of $E(\Xi)$.

$\kappa \quad$ Specific energy consumption of desalination plants $\left(\mathrm{kWh} / \mathrm{m}^{3}\right)$.

$E_{\text {desal }, w} \quad$ Volume of desalinated water $\left(\mathrm{m}^{3}\right)$.
$P_{\text {desal }, w} \quad$ Flow of desalinated water $\left(\mathrm{m}^{3} / \mathrm{h}\right)$.

$E_{\text {desal,e }} \quad$ Electrical energy required to produce $E_{\text {desal,w }}$ (kWh).

$P_{\text {desal,e }} \quad$ Electrical power equivalent to $P_{\text {desal }, w}(\mathrm{~kW})$.

$c_{u}^{c a p}, c_{y}^{r e p} \quad$ Capital and replacement cost per unit (\$/unit).

$c_{y}^{o \& m} \quad$ Yearly operation and maintenance cost per unit (\$/unit-yr).

$s_{y} \quad$ Salvage value per unit (\$/unit).

$C_{y}^{c a p}, C_{y}^{r e p}$ Present worth of the capital and replacement costs (\$/unit).

$C_{y}^{o \& m} \quad$ Present worth of the operation and maintenance cost (\$/unit).

$S_{y} \quad$ Present worth of the salvage value (\$/unit).

$C_{y} \quad$ Total present worth of all cost components (\$/unit).

$N_{y}, N_{y}^{r e m}$ Component life, component remaining life at end of project (Years).

$n r_{y} \quad$ Number of component replacements.

$i, f \quad$ Interest and inflation rates (\%).

$N_{p}, n \quad$ Project life time and index year (Years).

$c_{o i l}, \pi_{\text {oil }} \quad$ Production cost and global price of a barrel of oil (\$).

$c_{g}^{f u e l,(-,+)}$ Yearly grid fuel cost paid/displaced per unit energy (\$/Wh-yr).

$c_{g}^{o \& m} \quad$ Yearly operation and maintenance cost of the grid per unit energy (\$/Wh-yr).

$C_{g}^{f u e l,(-,+)}$ Present worth of grid fuel cost paid/displaced per unit energy $(\$ / W h)$.

$C_{g}^{o \& m} \quad$ Present worth of operation and maintenance cost of the grid per unit energy $(\$ / \mathrm{Wh})$.

$\lambda_{g}^{-}, \lambda_{g}^{+} \quad$ Total present worth of all grid cost components paid/displaced per unit energy.

$E_{b b l} \quad$ Equivalent energy from a barrel of oil (MWh).

Cost $_{\text {hyd }}$ Total present worth of the hybrid systems (\$).

$E_{e q}^{\omega} \quad$ Equivalent energy displaced from conventional generators in scenario $\omega(\mathrm{MWh})$.

$E_{t k, l v l}^{\omega}, P_{t k}^{\omega}$ Water tank level and flow in scenario $\omega\left(\mathrm{m}^{3}\right.$, $\left.\mathrm{m}^{3} / \mathrm{h}\right)$.

$\Delta t \quad$ Simulation step size (hour).

$S O C_{b a t}^{\text {min }}$ Minimum allowable state of charge (kWh).

$S O C_{\text {bat }}^{\omega} \quad$ State of charge in scenario $\omega(\mathrm{kWh})$.

$P_{b a t}^{\omega} \quad$ Battery power flow in scenario $\omega(\mathrm{kW})$.

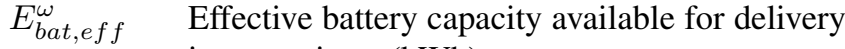
in scenario $\omega(\mathrm{kWh})$.

$P_{g}^{\omega}, P_{d u m p}^{\omega}$ Grid and dumped power in scenario $\omega$ (MW).

$\omega, \Omega, N_{\Omega} \quad$ Scenario index, scenario set and number of 


\begin{tabular}{|c|c|}
\hline$x_{p v}, x_{w t}$ & Number of PVs and WTGs (Units). \\
\hline$x_{t k}, x_{d}$ & $\begin{array}{l}\text { Water storage size and desalination plant ca- } \\
\text { pacity }\left(\mathrm{m}^{3}, \mathrm{~m}^{3} / \mathrm{h}\right) \text {. }\end{array}$ \\
\hline$x_{\text {bat }}$ & Battery storage size (MWh). \\
\hline$e, w$ & Electric and water notations. \\
\hline$\underline{P}_{g}, \bar{P}_{g}$ & Grid minimum and maximum power (MW). \\
\hline$P_{g}^{d n}, P_{g}^{u p}$ & Grid down and up ramp rates (MW). \\
\hline$u$ & Set of labels which include $\{p v, w t, t k, d, b a t\}$ \\
\hline$y$ & Set of labels which include $\{p v, w t, b a t\}$ \\
\hline $\begin{array}{l}\text { Pvited } \\
\text { pvarm }\end{array}$ & Rated power of the solar farm (MW). \\
\hline $\begin{array}{l}\text { Pated } \\
\text { wt,farm }\end{array}$ & Rated power of the wind farm (MW). \\
\hline$E_{\text {re,tot }}^{\text {year }}$ & $\begin{array}{l}\text { Total energy produced by the renewable re- } \\
\text { sources (MWh). }\end{array}$ \\
\hline$E_{\text {re,del }}^{\text {year }}$ & $\begin{array}{l}\text { Renewable energy delivered to the loads } \\
\text { (MWh). }\end{array}$ \\
\hline$E_{\text {tot }}^{\text {year }}$ & $\begin{array}{l}\text { Total energy produced by the grid and the } \\
\text { renewable energy resources }(\mathrm{MWh}) \text {. }\end{array}$ \\
\hline$R F_{\text {nom }}$ & Nominal renewable fraction $(\%)$. \\
\hline$R F_{\text {true }}$ & newable fraction $(\%)$. \\
\hline$U F$ & Hybrid system utilization factor (\%) \\
\hline
\end{tabular}

\section{INTRODUCTION}

$\mathbf{T}$ HIS paper was motivated mainly by the factors which would allow for faster incorporation of renewable energy resources to displace the traditional fossil-fuel energy sources. These factors are divided into three different aspects. First, is the rapid decline in the cost of renewable energy sources and their associated components. The second factor can be attributed to the increasing pressure to transition from fossil fuel energy sources which have detrimental environmental effects towards more sustainable sources. A third aspect can be introduced in countries which are blessed with an enormous amount of fossil fuel resources, where the preservation of these limited natural resources is of paramount importance to the country that holds it. The paper includes the Kingdom of Saudi Arabia as the primary case study. The kingdom is considered to be one of the countries with an abundance of fossil-fuel reserves. One of the critical barriers to incorporate renewable resources is their variability and uncertainty. Variability is defined as the continuous fluctuation of power generation based on the availability of primary fuel source (solar radiation, wind). Uncertainty is related to the magnitude and timing of the renewable generation output being less predictable than conventional power generation systems [1], [2].

These barriers can be dealt with in two different aspects. The first point is from the source's side where hybridization of solar photovoltaic and wind turbine generators can be used to reduce the level of uncertainty. As these two renewable sources are often looked at as a negatively correlated sources. The second point is on the load's side. The unique features of Saudi Arabia are primarily the availability of solar radiation and wind speed as well as high percentage of electrical loads which can be controlled such as energy-intensive desalination plants [3]. This feature, in particular, provides a massive driver for renewables to penetrate the electricity generation mixture.
The issue of renewable sources variability can be mitigated and reduced with an optimized operation strategy. Therefore, the paper tends to define and model electrical loads by how susceptible they are to the time of service.

Water resources in Saudi Arabia are scarce, and the demand for freshwater cannot be fulfilled from natural water resources only this led the kingdom to invest heavily in other solutions, primarily water desalination technologies. The Kingdom of Saudi Arabia holds the title for the largest producer of desalinated water, with a desalinated water production of 1.1076 billion $\mathrm{m}^{3}$ in 2014 [4].

Energy storage systems (ESS) are considered to be one of the main solutions for handling renewable energy fluctuations and uncertainty. ESS can serve the electrical network at different time frames. From short duration system regulation to several days worth of energy supply [5].

Different types of storage systems were investigated in the literature. Typically energy storage systems are classified based on the form by which the energy is stored. This includes electrochemical, thermal, mechanical and electromagnetic [6]. The authors in [7], proposed a wind farm coupled with pumped hydro storage (PHS) to serve a desalination plant. The main objective was to minimize the total system cost while maximizing the utilization of the power output from the wind farm. Cleary et al. [8] investigated the economic benefits of integrating compressed air energy storage system (CAES) with onshore wind energy which yielded an increase in revenues. Renewable energy serving desalination plants has been widely investigated especially in the middle eastern region. In [9] the authors performed a feasibility study of a stand alone PV system supplying a water desalination plant. Two desalination technologies were studied; reverse osmosis (RO) and electrodialysis reversal (EDR). The conclusion was that for low salinity water a soar-powered EDR system is more cost efficient than a RO system. With higher saintly water treatment, RO technique provided a lower overall system cost than the EDR system. Murat in [10], investigated the economics of different system configuration comprising of seven hybrid renewable energy system supplying a RO water desalination plant.

The types of loads considered are summarized as nondeferrable such as typical electrical loads in which the demand must be satisfied instantly, semi-deferrable loads which they share the same features as the non-deferrable, however, a storage medium is available to store energy for later usage. This category of loads is represented by a water desalination plant with a water tank storage or a Battery Energy Storage System (BESS).

The justification for increasing the penetration of renewable sources into the existing grid in countries with abundant fossil fuel might not be evident. However, this paper provides both economic and technical justifications and incentives to approach a more sustainable energy mix where the authors demonstrated in [11] that a net oil exporter countries would receive economic benefits by adopting sustainable energy systems.

Heuristic optimization methodologies are utilized to solve the developed problem which provides a fixable approach to 
solve complex optimization problems [12].

The paper aims to derive an objective function for a generation expansion planning (GEP) problem that can treat both a net oil importer or exporter. Also the introduction of alternative means of storing energy in terms of product storage (water) rather than storing excess renewable energy in typical BESS.

The paper is structured as follows: section II defines the renewable energy sources and their mathematical model. Section III addresses the modeling of the system loads. Section IV describes the mathematical formulation of the proposed system. Section V provides the solution methodology of the optimization problem and case studies were performed and demonstrated in section VII. The paper conclusions are discussed in section VIII.

\section{Renewable Resources Modeling}

\section{A. PV System}

A model which is commonly found in the literature for the PV panel power output is shown below [13]:

$$
\begin{gathered}
T_{C}=T_{A}+\left(\frac{N O C T-20}{0.8}\right) G_{T}, \\
P_{p v}=P_{m p p}^{r e f}\left(\frac{G_{T}}{G_{r e f}}\right)\left[1+\alpha_{P_{m p p}}\left(T_{C}-T_{C}^{r e f}\right)\right] \eta_{c o n v} d_{p v},
\end{gathered}
$$

\section{B. WTG System}

The power curve of the WTG is used to calculate the power output from a single WTG as follows [14]:

$$
P_{w t}= \begin{cases}P_{w t}^{\text {rated }}\left(\frac{v^{3}-v_{c i}^{3}}{v_{r}^{3}-v_{c i}^{3}}\right) \eta_{c o n v}, & \text { if } v_{c i}<v<v_{r} \\ P_{w t}^{r a t e d} \eta_{c o n v}, & \text { if } v_{r} \leq v \leq v_{c o} \\ 0, & \text { otherwise }\end{cases}
$$

\section{Solar Radiation and Wind Speed Forecast Error}

The solar radiation and wind speed forecast errors are modeled as random variables following a normal distribution similar to the models used in [15], [16]:

$$
\begin{gathered}
\varepsilon_{g}, \varepsilon_{v} \sim N(0,2), \\
G_{T}^{\text {new }}=G_{T}+\varepsilon_{g}, \quad v^{\text {new }}=v+\varepsilon_{v},
\end{gathered}
$$

The vectors of the forecast error of both the solar radiation and wind speed are the input to the Monte Carlo Simulation (MCS). Where samples are generated to capture the stochastic distribution of the objective in question (i.e., differential cost). The Coefficient of Variation (COV) is utilized as the stopping criteria for the MCS:

$$
\operatorname{COV}=\frac{\sigma[E(\Xi)]}{E(\Xi)} \leq \varepsilon,
$$

\section{LOAD MODELING}

Power system planning studies usually model the electric demand as a constant power within a specified time interval typically an hour [13]. All load demands are represented by an 8760-row vector.

\section{A. Conventional Load}

The conventional load here represents electrical demands that cannot be deferred or controlled. Therefore, this type of load is considered to have priority when the power is dispatched from the generators. This type of load is referred to as the non-deferrable $\left(\boldsymbol{P}_{c o n}\right)$.

\section{B. Water Desalination Plant}

To model desalination plants as an electrical power demand, the specific energy consumption per unit water volume is used. As reported in many studies [17]-[20], a one unit volume of desalinated water by reverse osmosis (RO) technology would require a certain amount of electrical energy. The desalination electrical load vector is represented by $\left(\boldsymbol{P}_{\text {desal }, e}\right)$.

$$
E_{\text {desal }, e}=\kappa E_{\text {desal }, w}, \quad \boldsymbol{P}_{\text {desal }, e}=\kappa \boldsymbol{P}_{\text {desal }, w},
$$

\section{Problem Statement and Mathematical FORMULATION}

The objective in this paper is to optimally penetrate the existing electric power grid with renewable energy sources which displace conventional fossil fuel generation in an oil exporting country.

\section{A. Cost Functions}

The cost functions included for PVs and WTGs are [21]:

$C_{y}^{o \& m}=c_{y}^{o \& m} \sum_{n=1}^{N_{p}}\left(\frac{1+f}{1+i}\right)^{n}, \quad C_{y}^{r e p}=c_{y}^{r e p} \sum_{r=1}^{n r_{y}}\left(\frac{1+f}{1+i}\right)^{r N_{y}}$,

The salvage value is also included and a linear depreciation model of the components is assumed.

$$
\begin{gathered}
S_{y}=s_{y}\left(\frac{1+f}{1+i}\right)^{N_{p}}, \quad s_{y}=c_{y}^{r e p}\left(\frac{N_{y}^{r e m}}{N_{y}}\right), \\
N_{y}^{r e m}=N_{y}-\left(N_{p}-n r_{y} N_{y}\right), \quad n r_{y}=\operatorname{INT}\left(\frac{N_{p}}{N_{y}}\right), \\
C_{y}=C_{y}^{c a p}+C_{y}^{o \& m}+C_{y}^{r e p}-S_{y},
\end{gathered}
$$

The water tank and desalination plant capacity upgrade, has only a capital cost associated with them. As for the legacy grid, it has two cost components, fuel cost in addition to operation and maintenance cost.

$$
\begin{gathered}
c_{g}^{f u e l,-}=\frac{c_{\text {oil }}}{E_{b b l}}, \quad c_{g}^{f u e l,+}=\frac{\left(\pi_{\text {oil }}-c_{\text {oil }}\right)}{E_{b b l}}, \\
C_{g}^{f u e l,(-,+)}=c_{g}^{f u e l,(-,+)} \sum_{n=1}^{N_{p}}\left(\frac{1+f}{1+i}\right)^{n}, \\
\lambda_{g}^{-}=C_{g}^{f u e l,-}+C_{g}^{o \& m}, \quad \lambda_{g}^{+}=C_{g}^{f u e l,+},
\end{gathered}
$$

The hybrid system cost Cost $_{\text {hyd }}$ depends on the system configuration selected:

$$
\text { Cost }_{h y d}=\sum_{y=p v, w t, b a t} C_{y} x_{y},(\mathrm{BESS})
$$

Cost $_{h y d}=\left(\sum_{y=p v, w t} C_{y} x_{y}\right)+C_{t k}^{c a p} x_{t k}+C_{d}^{c a p} x_{d}$, (Water storage) 


\section{B. Objective Function}

Differential system cost is the difference between the total system cost and the profit gained from displacing the grid supply. The cost savings are given by $B A U_{\text {cost }}-\Delta C$ ost.

$$
\Delta \text { Cost }=\text { Cost }_{\text {hyd }}+\frac{1}{N_{\Omega}} \sum_{\omega \in \Omega}(\underbrace{\lambda_{g}^{-} \sum_{t=1}^{T} P_{g}^{\omega}(t)}_{\text {Grid cost }}-\underbrace{\lambda_{g}^{+} E_{e q}^{\omega}}_{\substack{\text { Displacement } \\ \text { profit }}}),
$$

The above formulation represents the general form for cost objective function of renewable sources allocation problems. It also represents a net oil exporter country by which any barrel of oil displaced can be sold in the global market at a higher price. In a net oil importer countries, the displacement gain factor diminishes $\left(\lambda_{g}^{+}=0\right)$ and the cost objective function is reduced to:

$$
\text { Cost }=\text { Cost }_{h y d}+\frac{1}{N_{\Omega}} \sum_{\omega \in \Omega}(\underbrace{\left(\lambda_{g}^{-} \sum_{t=1}^{T} P_{g}^{\omega}(t)\right.}_{\text {Grid cost }}),
$$

The grid power is calculated based on the operation strategies which is discussed later.

\section{System Constraints}

1) Load balance: At any time instant $t$ the total supply must be sufficient to handle the required demand.

$$
\begin{aligned}
& P_{p v}^{\omega}(t) x_{p v}+P_{w t}^{\omega}(t) x_{w t}+\kappa P_{t k}^{\omega}(t)+P_{g}^{\omega}(t) \\
= & P_{\text {con }}(t)+P_{\text {desal }, e}(t)+P_{d u m p}^{\omega}(t), \quad \forall t, \forall \omega
\end{aligned}
$$

2) Water tank capacity and flow bounds: The amount of stored water at every time instant $t$ should not exceed the water tank capacity. This is mathematically represented in (20). The inequality constraint (21) indicates that the water flowing into the tank should do not exceed the desalination capability as well as the capacity of the storage tank. Also, the water flowing from the tank should do not exceed the capacity of the water tank or the water load which is represented by (22).

$$
\begin{gathered}
0 \leq E_{t k, l v l}^{\omega}(t) \leq x_{t k}, \quad \forall t, \forall \omega \\
0 \leq P_{t k, \text { in }}^{\omega}(t) \leq \min \left(x_{d}, x_{t k} / \Delta t\right), \quad \forall t, \forall \omega \\
0 \leq P_{t k, \text { out }}^{\omega}(t) \leq \min \left(P_{\text {desal }, w}(t), E_{t k, l v l}(t) / \Delta t\right), \quad \forall t, \forall \omega
\end{gathered}
$$

3) Battery energy storage system capacity and flow bounds: At any time instance, the total amount of stored energy should not exceed the batteries' capacity and should not as well reduce to below the minimum state of charge which is mathematically represented in (23). The inequality constraint (24) states that the power flow from or to the battery should do not exceed the batteries' capacity.

$$
\begin{gathered}
S O C_{\text {min }} \leq S O C_{b a t}^{\omega}(t) \leq x_{b a t}, \quad \forall t, \forall \omega \\
0 \leq P_{b a t}^{\omega}(t) \leq x_{b a t} / \Delta t, \quad \forall t, \forall \omega \\
E_{b a t, e f f}^{\omega}(t)=S O C_{b a t}^{\omega}(t)-S O C_{b a t}^{\text {min }}, \quad \forall t, \forall \omega
\end{gathered}
$$

4) Legacy grid power and ramp bounds: The amount of grid power and ramp rates must be within a specified range.

$$
\begin{aligned}
\underline{P}_{g} & \leq P_{g}^{\omega}(t) \leq \bar{P}_{g}, \quad \forall t, \forall \omega \\
-P_{g}^{d n} & \leq \Delta P_{g}^{\omega}(t) \leq P_{g}^{u p}, \quad \forall t, \forall \omega
\end{aligned}
$$

5) Decision variables bounds and type: All decision variables which are the outcomes from the optimization problem are integers and restricted to a specific range. The decision variables for the system configuration with BESS includes $x_{p v}, x_{w t}$ and $x_{b a t}$. As for the system configuration with water storage, the decision variables are $x_{p v}, x_{w t}, x_{t k}$ and $x_{d}$.

$$
x_{u}^{\min } \leq x_{u} \leq x_{u}^{\max }, \quad x_{u} \in \text { Integers }, \quad \forall u
$$

\section{Operation Strategy of The System With BESS}

The generated power from the renewable resources has the priority to serve the loads. The excess power after serving all instantaneous demand is directed towards the BESS. Figure 1 demonstrates a simplified system configuration with a battery energy storage system. The operation strategy is performed for every time step and the flow chart of the operation for a system configuration with BESS is shown in figure 2

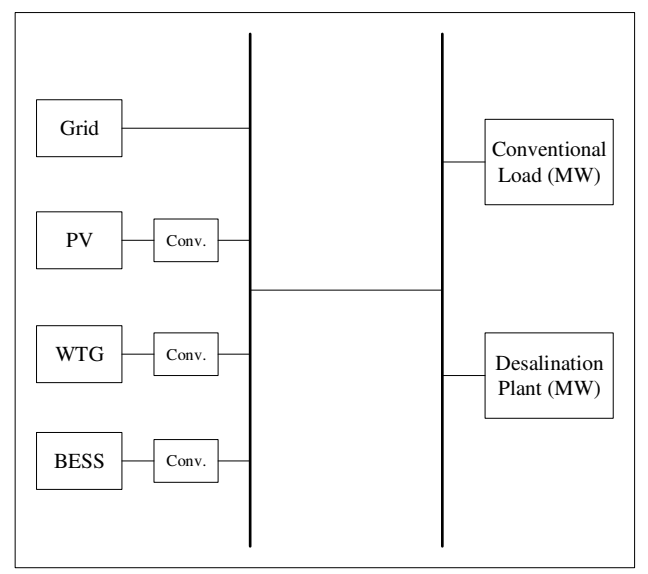

Fig. 1. System configuration with BESS

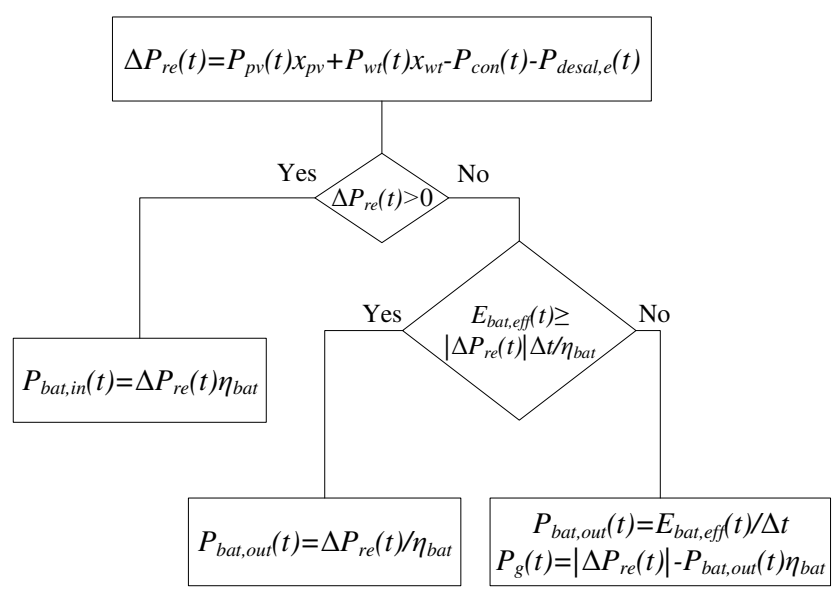

Fig. 2. Operation strategy flow chart of system configuration with BESS 
The level of available energy in the battery for the next time step is: level of available water in the storage tank for the next time step is:

$S O C_{b a t}(t+1)=\left\{\begin{array}{ll}S O C_{b a t}(t)+P_{b a t, i n}(t) \Delta t & \text { if } \Delta P_{r e}(t)>0 \\ S O C_{b a t}(t)-P_{b a t, o u t}(t) \Delta t & \text { if } \Delta P_{r e}(t)<0\end{array} E_{t k, l v l}(t+1)= \begin{cases}E_{t k, l v l}(t)+P_{t k, i n}(t) \Delta t & \text { if } \Delta P_{r e}^{2}(t)>0 \\ E_{t k, l v l}(t)-P_{t k, \text { out }}(t) \Delta t & \text { if } \Delta P_{r e}^{1}(t)<0\end{cases}\right.$

\section{E. Operation Strategy of The System With Water Tank}

The power output from the renewable resources has the priority to serve the loads over the legacy grid. Any excess power after serving all instantaneous demand is diverted towards the desalination plant to be stored as desalinated water. Figure 3 demonstrates a simplified system configuration with water storage. The operation strategy is performed for every time step, and the flow chart of the operation for a system configuration with water storage is shown in figure 4 .

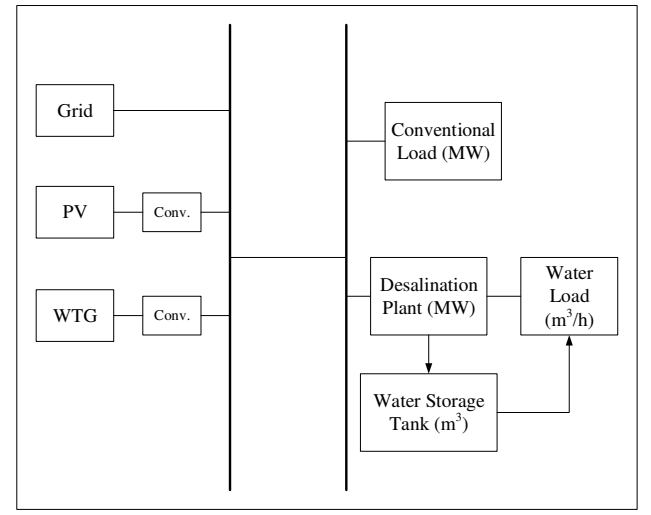

Fig. 3. System configuration with water storage tank
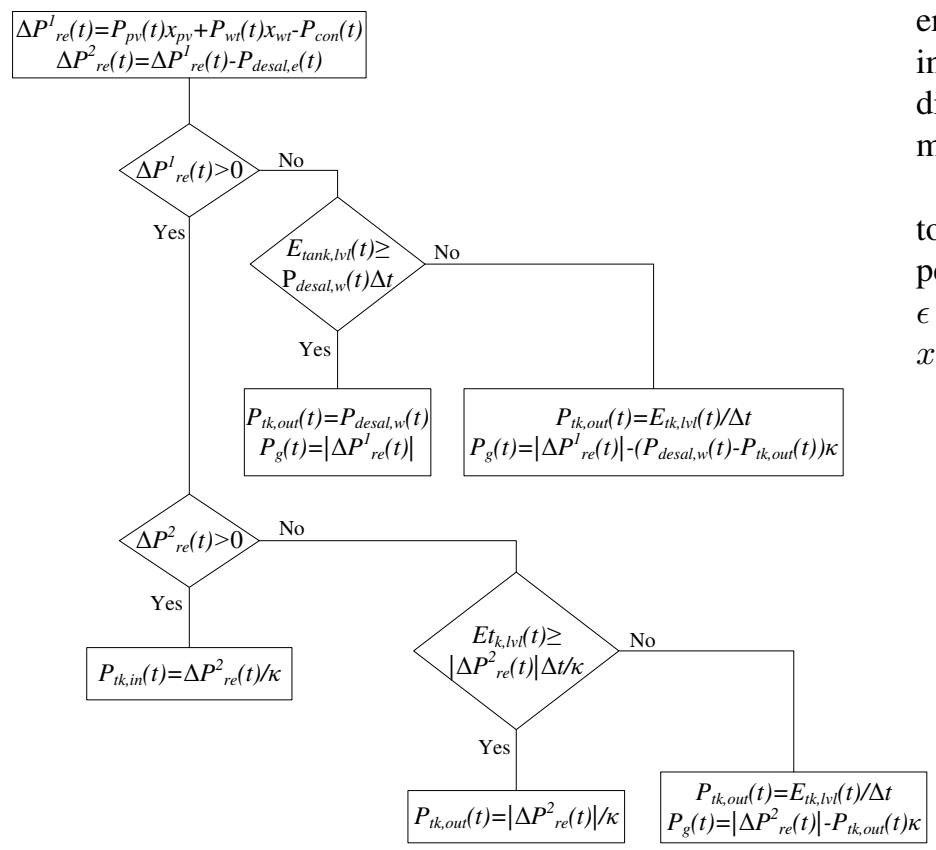

Fig. 4. Operation strategy flow chart of system configuration with water storage tank

\section{Mutation Based Particle Swarm Optimization}

The PSO algorithm starts by randomly generating different particles. Each particle has a position and a velocity associated with it. First, the velocity of each particle is calculated followed by the calculation of its position. Each particle has its memory of the best position it ever reached regarding the objective function value $P_{j, b}$. Another memory is reserved for the best position ever reached by any particle which is referred to as the global best solution $G_{b}$. The operation is repeated for a predefined number of iterations $I$ [22]-[24].

\section{A. Algorithm Operators}

$$
\begin{gathered}
V_{j}(i)=w V_{j}(i-1)+c_{1} r_{1}\left(P_{j, b}-X_{j}(i-1)\right) \\
+c_{2} r_{2}\left(G_{b}-X_{j}(i-1)\right) \quad \forall j \in J \\
w=\left(\frac{\left(w_{2}-w_{1}\right) i}{I}\right)-w_{2} \\
c_{1}=\left(\frac{\left(c_{1}^{f}-c_{1}^{0}\right) i}{I}\right)+c_{1}^{0}, \quad c_{2}=\left(\frac{\left(c_{2}^{f}-c_{2}^{0}\right) i}{I}\right)+c_{2}^{0}
\end{gathered}
$$

The position of each particle $X_{j}$ is updated each iteration as follows:

$$
X_{j}(i)=X_{j}(i-1)+V_{j}(i) \quad \forall j \in J
$$

The velocity of particle $j$ at iteration $i$ is represented by $V_{j}(i)$. The variable $w$ is the inertia weight. The time varying acceleration coefficients are $c_{1}, c_{2}$ and the superscripts $0, f$ denotes initial and final values respectively. $r_{1}$ and $r_{2}$ are a uniformly distributed random numbers. $w_{2}, w_{1}$ are the maximum and minimum inertia weights.

Two mutation operators are adopted in the PSO optimization to enhance its ability to search. The mutation operator is only performed on the global best position at each iteration. Where $\epsilon$ and $\beta$ are normally, and beta distributed random numbers. $x_{k}$ is the decision variable to be mutated.

$$
x_{k}^{\text {mutated }}=x_{k}\left(1+\frac{1}{2} \epsilon\right), \quad x_{k}^{\text {mutated }}=x_{k}\left(1+\frac{1}{2} \beta\right)
$$

\section{Technical Parameters Calculation}

The technical metrics include the following:

$P_{p v, f a r m}^{\text {rated }}=P_{p v}^{r e f} \times x_{p v}, \quad P_{w t, f a r m}^{\text {rated }}=P_{w t}^{\text {rated }} \times x_{w t}$

$$
R F_{n o m}=\frac{E_{\text {re,tot }}^{\text {year }}}{E_{\text {tot }}^{\text {year }}} \times 100, \quad R F_{\text {true }}=\frac{E_{\text {rea, }, \text { del }}^{\text {year }}}{E_{\text {tot }}^{\text {year }}} \times 100
$$

$$
U F=\frac{R F_{\text {true }}}{R F_{\text {nom }}} \times 100
$$




\section{Case Studies And Sensitivity Results}

\section{A. System Data and Parameters}

The study is based on Yanbu city, on the western coast of the Kingdom of Saudi Arabia. The average daily solar radiation is $6.17 \mathrm{kWh} / \mathrm{m}^{2}$, and an average wind speed of $6.61 \mathrm{~m} / \mathrm{s}$ at hub height. The yearly total system load $E_{\text {load }}$ is estimated to be $2.51 \mathrm{TWh}$. The operational duration under consideration is ( $T=8760$ hours). The business as usual cost is $B A U_{\text {cost }}=$ $\lambda_{g}^{-} E_{\text {load }}=\$ 2.56$ Billion. The simulation algorithm is shown in figure 5 .

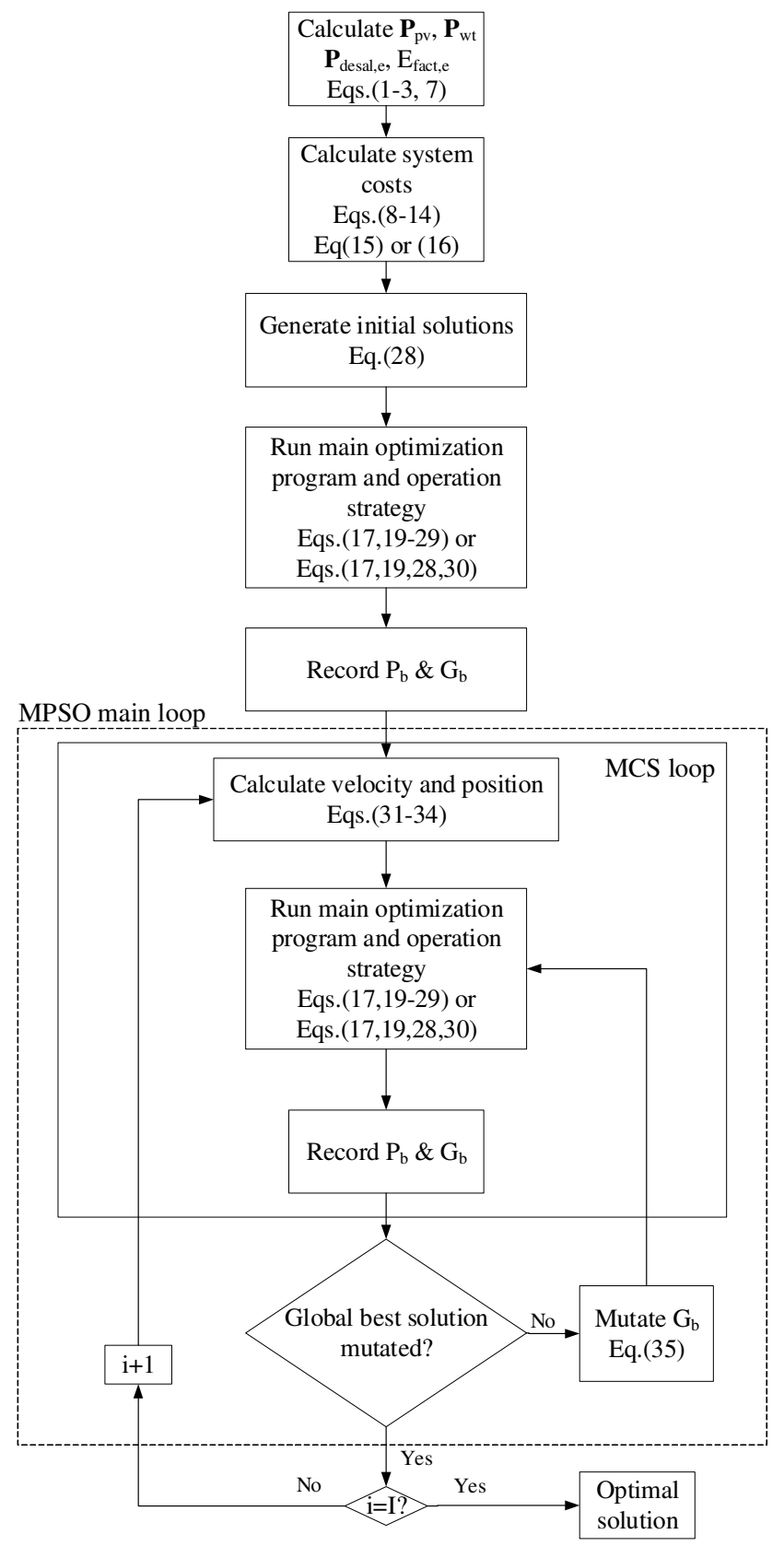

Fig. 5. Algorithm procedure using MPSO

\section{B. Simulation Results}

The simulations were carried out for both system configurations. The results are shown in Tables III, IV and V.
TABLE I

System Technical Parameters

\begin{tabular}{c|c}
\hline \hline Parameters & Values \\
\hline$P_{m p p}^{r e f}(\mathrm{~W})$ & 200 \\
\hline$\alpha_{P_{m p p}}\left(\% /{ }^{\circ} \mathrm{C}\right)$ & $-3.89 \times 10^{-3}$ \\
\hline$N O C T\left({ }^{\circ} \mathrm{C}\right)$ & 48.1 \\
\hline$\eta_{c o n v}, \eta_{b a t}, d_{p v}(\%)$ & $97,95,90$ \\
\hline$P_{w t}^{r a t e d}(\mathrm{MW})$ & 1.0 \\
\hline$v_{c i}, v_{r}, v_{c o}(\mathrm{~m} / \mathrm{s})$ & $3,12.5,25$ \\
\hline$\kappa(\mathrm{kWh})$ & 5 \\
\hline \hline
\end{tabular}

TABLE II

SySTEM ECONOMIC PARAMETERS

\begin{tabular}{c|c}
\hline \hline Parameters & Values \\
\hline$i, f(\%)$ & $2,2.1$ \\
\hline$N($ Years $)$ & 25 \\
\hline$c_{p v}^{c a p}, c_{w t}^{c a p}, c_{b a t}^{c a p}(\$ / \mathrm{kW})$ & $2014,1605,300$ \\
\hline$c_{p v}^{o \& m}, c_{w t}^{o \& m}, c_{b a t}^{o \& m}(\$ / \mathrm{kW}-\mathrm{yr})$ & $13,51,3$ \\
\hline$c_{p v}^{r e p}, c_{w t}^{r e p}, c_{b a t}^{r e p}(\$ / \mathrm{kW})$ & $75 \% c_{p v}^{c a p}, 75 \% c_{w t}^{c a p}, 75 \% c_{b a t}^{c a p}$ \\
\hline$c_{t k}^{c a p}, c_{d}^{c a p}\left(\$ / \mathrm{m}^{3}\right)$ & 50,900 \\
\hline$c_{g}^{o \& m}(\$ / \mathrm{MWh})$ & 24 \\
\hline$c_{o i l}, \pi_{o i l}(\$ / \mathrm{bbl})$ & 9,50 \\
\hline \hline
\end{tabular}

TABLE III

OPTIMIZATION RESULTS FOR SySTEM CONFIGURATION WITH BESS

\begin{tabular}{c|c|c|c|c}
\hline \hline $\begin{array}{c}\Delta \text { Cost } \\
\text { (Billion\$) }\end{array}$ & $\begin{array}{c}x_{p v} \\
(\mathrm{MW})\end{array}$ & $\begin{array}{c}x_{w t} \\
(\mathrm{MW})\end{array}$ & $\begin{array}{c}x_{\text {bat }} \\
(\mathrm{MWh})\end{array}$ & $\begin{array}{c}E_{\text {grid }} \\
(\mathrm{MWh})\end{array}$ \\
\hline 1.17 & 1641728 & 336 & 88 & $1.35 \times 10^{6}$ \\
\hline \hline
\end{tabular}

TABLE IV

OPTIMIZATION RESULTS FOR SYSTEM CONFIGURATION WITH WATER STORAGE TANK

\begin{tabular}{c|c|c|c|c|c}
\hline \hline $\begin{array}{c}\Delta \text { Cost } \\
\text { (Billion\$) }\end{array}$ & $\begin{array}{c}x_{p v} \\
\text { (Units) }\end{array}$ & $\begin{array}{c}x_{w t} \\
(\text { Units })\end{array}$ & $\begin{array}{c}x_{t k} \\
\left(\mathrm{~m}^{3}\right)\end{array}$ & $\begin{array}{c}x_{d} \\
\left(\mathrm{~m}^{3} / \mathrm{h}\right)\end{array}$ & $\begin{array}{c}E_{\text {grid }} \\
(\mathrm{MWh})\end{array}$ \\
\hline 1.137 & 1810082 & 334 & 199992 & 10551 & $1.30 \times 10^{6}$ \\
\hline \hline
\end{tabular}

TABLE V

TECHNICAL AND ECONOMICAL METRICS FOR THE SYSTEM CONFIGURATION WITH A WATER TANK

\begin{tabular}{|c|c|c|c|c|c|}
\hline $\begin{array}{c}\text { Cost savings } \\
\text { (Billion\$) }\end{array}$ & $\begin{array}{c}P_{p v, f a r m}^{\text {rated }} \\
\text { (MW) }\end{array}$ & $\begin{array}{c}P_{\text {wt,farm }}^{\text {rated }} \\
\text { (MW) }\end{array}$ & $\begin{array}{c}R F_{\text {nom }} \\
\quad \%)\end{array}$ & $\begin{array}{c}R F_{\text {true }} \\
(\%)\end{array}$ & $\begin{array}{l}\text { UF } \\
(\%)\end{array}$ \\
\hline 1.423 & 362.01 & 344 & 57.02 & 48.2 & 84.54 \\
\hline
\end{tabular}

\section{Sensitivity Analysis}

The sensitivity analysis performed by introducing percentage variation on key variables. The variables include, solar radiation, wind speed in addition to the price of oil in a global market. The results are shown in figure 6 . 


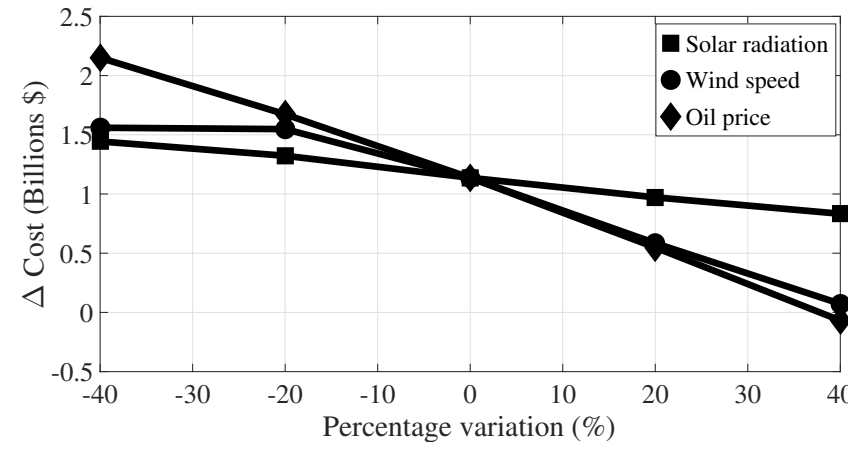

Fig. 6. Variation of differential cost with solar radiation, wind speed and export oil prices

\section{Results Discussion}

Two system configurations were simulated. The first configuration comprised of a hybrid (wind and solar) renewable energy sources connected to an existing grid with a battery energy storage system. The second system included a grid connected hybrid system as well without a battery energy storage system. Instead, a water storage tank is used at the water desalination plant to provide storage capabilities. While the grid integrated renewable system coupled with BESS yielded an economical solution (Table III), a lower differential cost was also possible as the system configuration coupled with a water storage tank (Tables IV and V) provided an even lower overall differential cost. About 50\% of the energy supplied to the loads is from the renewable sources which is indicated by $\left(R F_{\text {true }}\right)$ and more than $80 \%$ of energy produced from the renewables were utilized (UF).

The sensitivity/scenario analysis (Figure 6) demonstrated the behavior of the planning problem under different circumstances. The three variables chosen for this study are the solar radiation wind speed and the global prices of oil. These variables are all plotted on the same figure to give a clear demonstration of their behavior compared with each other, where the slope of the plots shows the level of sensitivity. Clearly the solar radiation has the lowest impact on the differential cost among the three variables. The figure shows the differential cost $(\triangle C$ ost $)$ varying from approximately $\$ 1.5$ Billion to almost $\$ 800$ Million with a solar radiation variation of $\pm 40 \%$. The sensitivity of the differential cost with wind speed did not change for a reduction of 40 and 20 percent in wind speed. This is an indication that wind turbine generators are not economical with lower wind speeds than the expected values and hence the optimization solution for those two scenarios are the same. At higher than expected wind speeds $+20 \%$ and $+40 \%$, the differential cost rapidly decreases to almost net neutral. This means that the profits gained from displacing oil barrels for grid usage are able to cover the expenses of building a hybrid renewable system and supply the load. The oil prices have the highest impact on the differential cost. An important point to make is at $+40 \%$ increase in oil prices the differential cost becomes negative, this means that the profit made by displacing oil usage for grid generation is higher than the total cost required for constructing the hybrid renewable system and load grid supply.

\section{CONCLUSION}

This paper aims to provide an economical validation for introducing sustainable energy sources in a net oil exporting country. The motivations for this transition are the low production cost of oil within the Kingdom of Saudi Arabia and the higher value of oil in the global market. The typical hybrid renewable system includes PVs, WTGs, and BESS, this paper investigated the load properties of a specific location (i.e., Saudi Arabia) and proposed alternative energy storage. With a high percentage of energy-intensive desalination plants in the kingdom, storing the excess renewable energy as water which is a product from the available energy provides a more reliable and cost-efficient solution. This conclusion leads to the investigation of other types of loads which can utilize different means of storage at a lower cost than the typical BESS.

\section{ACKNOWLEDGMENT}

The authors would like to thank King Abdulaziz City for Science and Technology (KACST), Riyadh, Saudi Arabia for their support.

\section{REFERENCES}

[1] M. H. Nehrir, C. Wang, K. Strunz, H. Aki, R. Ramakumar, J. Bing, Z. Miao, and Z. Salameh, "A review of hybrid renewable/alternative energy systems for electric power generation: Configurations, control, and applications," IEEE Transactions on Sustainable Energy, vol. 2, no. 4, pp. 392-403, 2011.

[2] N. Intermittent and V. G. T. Force, "Accommodating high levels of variable generation," North American Electric Reliability Corp.(NERC), 2009.

[3] L. Bird, M. Milligan, and D. Lew, "Integrating variable renewable energy: challenges and solutions," National Renewable Energy Laboratory, 2013.

[4] Electricity and Cogeneration Regulatory Authority, "Activities and achievements of the authority in 2014," report, 2014.

[5] Electric Power Research Institute, "Electric power system flexibility: Challenges and opportunities," report, 2016.

[6] H. Zhao, Q. Wu, S. Hu, H. Xu, and C. N. Rasmussen, "Review of energy storage system for wind power integration support," Applied Energy, vol. 137, pp. 545-553, 2015.

[7] R. Segurado, J. F. A. Madeira, M. Costa, N. Duić, and M. G. Carvalho, "Optimization of a wind powered desalination and pumped hydro storage system," Applied Energy, vol. 177, pp. 487-499, 2016.

[8] B. Cleary, A. Duffy, A. OConnor, M. Conlon, and V. Fthenakis, "Assessing the economic benefits of compressed air energy storage for mitigating wind curtailment," IEEE Transactions on Sustainable Energy, vol. 6, no. 3, pp. 1021-1028, 2015.

[9] N. Ghaffour, J. Bundschuh, H. Mahmoudi, and M. F. A. Goosen, "Renewable energy-driven desalination technologies: A comprehensive review on challenges and potential applications of integrated systems," Desalination, vol. 356, pp. 94-114, 2015.

[10] M. Al-Nory and M. El-Beltagy, "An energy management approach for renewable energy integration with power generation and water desalination," Renewable Energy, vol. 72, pp. 377-385, 2014.

[11] A. A. Almehizia, H. M. Al-Masri, and M. Ehsani, "Feasibility study of sustainable energy integration in a fossil fuel rich country," in 2018 IEEE Industry Applications Society Annual Meeting (IAS), pp. 1-6.

[12] A. González, J.-R. Riba, A. Rius, and R. Puig, "Optimal sizing of a hybrid grid-connected photovoltaic and wind power system," Applied Energy, vol. 154, pp. 752-762, 2015.

[13] Y. M. Atwa, E. F. El-Saadany, M. M. A. Salama, R. Seethapathy, M. Assam, and S. Conti, "Adequacy evaluation of distribution system including wind/solar dg during different modes of operation," IEEE Transactions on Power Systems, vol. 26, no. 4, pp. 1945-1952, 2011.

[14] M. Sathyajith, Wind Energy: Fundamentals, Resource Analysis and Economics. Springer Berlin Heidelberg, 2006. 
[15] F. Bouffard and F. D. Galiana, "Stochastic security for operations planning with significant wind power generation," in 2008 IEEE Power and Energy Society General Meeting - Conversion and Delivery of Electrical Energy in the 21st Century, pp. 1-11.

[16] Y. Xu, Q. Hu, and F. Li, "Probabilistic model of payment cost minimization considering wind power and its uncertainty," IEEE Transactions on Sustainable Energy, vol. 4, no. 3, pp. 716-724, 2013.

[17] A. Al-Karaghouli and L. L. Kazmerski, "Energy consumption and water production cost of conventional and renewable-energy-powered desalination processes," Renewable and Sustainable Energy Reviews, vol. 24, pp. 343-356, 2013

[18] P. C. M. Carvalho, L. A. D. Carvalho, J. J. H. Filho, and R. S. H. Oliveira, "Feasibility study of photovoltaic powered reverse osmosis and pumping plant configurations," IET Renewable Power Generation, vol. 7 no. 2, pp. 134-143, 2013 .

[19] E. M. A. Mokheimer, A. Z. Sahin, A. Al-Sharafi, and A. I. Ali, "Modeling and optimization of hybrid wind-solar-powered reverse osmosis water desalination system in saudi arabia," Energy Conversion and Management, vol. 75, pp. 86-97, 2013.

[20] N. Ghaffour, S. Lattemann, T. Missimer, K. C. Ng, S. Sinha, and G. Amy, "Renewable energy-driven innovative energy-efficient desalination technologies," Applied Energy, vol. 136, pp. 1155-1165, 2014.

[21] L. Wang and C. Singh, "Multicriteria design of hybrid power generation systems based on a modified particle swarm optimization algorithm," IEEE Transactions on Energy Conversion, vol. 24, no. 1, pp. 163-172, 2009.

[22] R. Eberhart and J. Kennedy, "A new optimizer using particle swarm theory," in Micro Machine and Human Science, 1995. MHS '95., Proceedings of the Sixth International Symposium on, pp. 39-43.

[23] S. Rao and S. Rao, Engineering Optimization: Theory and Practice. Wiley, 2009

[24] H. Wang, W. Wang, and Z. Wu, "Particle swarm optimization with adaptive mutation for multimodal optimization," Applied Mathematics and Computation, vol. 221, pp. 296-305, 2013.

Abdullah Almehizia (S'14) received his B.Eng. degree from King Saud University. Riyadh, Saudi Arabia in 2010, and the MEng degree from University of Calgary, Calgary, Canada in 2014. He is currently pursuing his Ph.D. degree at Texas A\&M University in, College Station, USA. His main research interests are related to renewable energy resources integration and optimization, Power system planning, reliability and economics.

Hussein M. K. Al-Masri (S'14-M'16) received the B.Sc. and M.S. degrees in electrical power engineering from Yarmouk University, Irbid, Jordan, in 2010 and 2012, respectively, and the Ph.D. degree in electrical engineering from Texas A\&M University, College Station, TX, USA, in 2016.He was a Lab Manager and Researcher at the Sustainable Energy and Vehicle Engineering Program, Power Electronics and Motor Drives Laboratory, Texas A\&M University. He is currently an Assistant Professor with the Electrical Power Engineering Department, Yarmouk University, Jordon. His research interests include renewable retrofitting energy systems, power electronics and photovoltaic applications, and the applications of artificial intelligence techniques to solve power system problems.Dr. Al-Masri received the 2016 Outstanding Graduate Teaching Fellowship from the Department of Electrical Engineering at Texas A\&M University.

Mehrdad Ehsani (S'70-M'81-SM'83-F'96-LF2015). Ehsani is the Robert M. Kennedy Professor of Electrical Engineering at Texas A\&M University. $\mathrm{He}$ is the co-author of more than 400 technical papers, 17 books, an IEEE standards book, and 30 US and EU patents. He has won over 130 prize paper and other awards in IEEE and others, including IEEE-VTS Avant Garde Award for his contributions to the hybrid electric vehicle technology and the 2003 IEEE field award in Undergraduate teaching. Ehsani has lead several international conferences and has served on the governing bodies of IEEE Power Electronics Society, Industry Applications Society, and Vehicular Technology Society. He is a Life Fellow of IEEE, a Fellow of SAE, a Distinguished Speaker of several IEEE societies, a consultant to over 60 US and international companies and government agencies, and a registered Professional engineer in the state of Texas. 